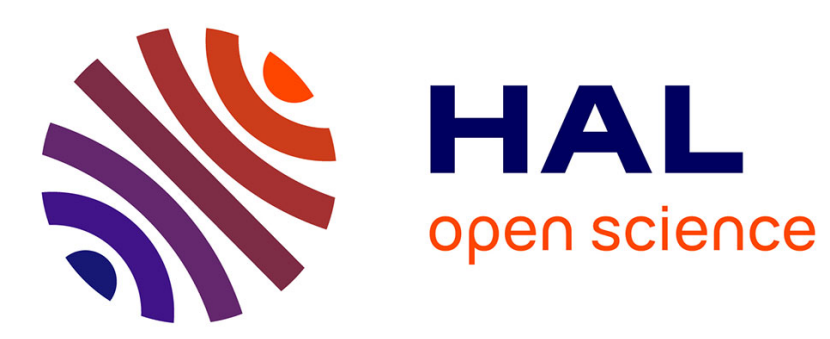

\title{
Predictive control based on nonlinear observer for muscular force and fatigue model
}

\author{
Toufik Bakir, Bernard Bonnard, Sami Othman
}

\section{To cite this version:}

Toufik Bakir, Bernard Bonnard, Sami Othman. Predictive control based on nonlinear observer for muscular force and fatigue model. ACC 2018 - The 2018 American Control Conference, Jun 2018, Milwaukee, United States. pp.2157-2162, 10.23919/ACC.2018.8430962 . hal-01591187v2

\section{HAL Id: hal-01591187 \\ https://hal.science/hal-01591187v2}

Submitted on 23 Feb 2018

HAL is a multi-disciplinary open access archive for the deposit and dissemination of scientific research documents, whether they are published or not. The documents may come from teaching and research institutions in France or abroad, or from public or private research centers.
L'archive ouverte pluridisciplinaire HAL, est destinée au dépôt et à la diffusion de documents scientifiques de niveau recherche, publiés ou non, émanant des établissements d'enseignement et de recherche français ou étrangers, des laboratoires publics ou privés. 


\title{
Predictive Control Based on Nonlinear Observer for Muscular Force and Fatigue Model
}

\author{
T.Bakir ${ }^{1}$, B. Bonnard ${ }^{2}$ and S. Othman ${ }^{3}$
}

\begin{abstract}
The Functional Electrical Stimulation (FES) is used in the case of neurological disorders (paralyzed muscles) or the muscle reinforcement (sportsmen). A recent model was proposed coupling a force model and a fatigue model. Based on the specific structure of the model, we present a predictive control scheme using online estimation of the fatigue variables with a nonlinear observer. It is numerically tested in a preliminary study.
\end{abstract}

\section{INTRODUCTION}

Functional Electrical Stimulation (FES) consists of sending an electrical stimulation to the muscle in order to produce functional movements. FES can be used for muscular reinforcement or for muscles reeducation. In the case of paralysis, FES led to activate the paralyzed muscles to produce movements. However, current FES-system induces a muscular fatigue and imprecise movements [1].

The simplest models are force models of [2], [3] and a more sophisticated model was proposed by [4], [5], [6], [7] where the force model is coupled to the fatigue model. This led to a five dimensional set of differential equations where the input is a train of electrical stimulations whose aim is to produce a force response.

Only few works used Ding model to design an optimized train of pulses to control the force level. [8], [9], [10] used a Model-Free Control (MFC), a predictive strategy (experimental case) and a nonlinear technique (input output linearization) to control the force level, respectively.

Our contribution is to make a preliminary analysis of the control problem in the frame of development of recent techniques in nonlinear control based on the design of a highgain nonlinear observer, adapting the technique of [11] to our study to perform an inline fatigue parameters estimation. It is used to design a predictive control and improving the results of [10]. A sequence of preliminary numeric simulations is presented to validate the pertinence of the techniques.

The article is organized in 4 sections. In section 2, the force-fatigue model is presented and analyzed. In section 3, a prior estimation of the sensitivity of the fatigue variablesparameters are analyzed and used to the design of the highgain nonlinear observer. The predictive control scheme is presented. The final section 4 is devoted to the numerical study of the force control problem to bring the force to

\footnotetext{
${ }^{1}$ Univ. Bourgogne Franche-Comté, Le2i Laboratory UMR 6306, CNRS, Arts et Métiers, Dijon, France (e-mail: toufik.bakir@u-bourgogne.fr).

${ }^{2}$ Univ. Bourgogne Franche-Comté, IMB Laboratory UMR CNRS 5584, Dijon, and INRIA team Mc TAO, Sophia Antipolis, France (e-mail: Bernard.Bonnard@u-bourgogne.fr)

${ }^{3}$ Univ. Claude Bernard Lyon1, LAGEP Laboratory UMR CNRS 5007, Villeurbanne, France (sami.othman@univ-lyon1.fr)
}

the reference force based on the inline estimation of the fatigue state variables. Note that it is a preliminary control strategy aiming to test the validity of the observer to provide more sophisticated optimal control strategy for this specific problem.

\section{MATHEMATICAL FORCE-FATIGUE MODEL}

We consider the force-fatigue model developed by [6], [7], this model could be decomposed in two subsystems. The first system is the force model, where the force is controlled using the $C_{N}$ variable which takes into account the calcium kinetics and the calcium-troponin interaction during the muscle activation. It can be written as:

$$
\begin{gathered}
\frac{d C_{N}}{d t}=E_{s}(t)-\frac{C_{N}}{\tau_{c}} \\
\frac{d F}{d t}=A \frac{C_{N}}{K_{m}+C_{N}}-\frac{F}{\tau_{1}+\tau_{2} \frac{C_{N}}{K_{m}+C_{N}}} .
\end{gathered}
$$

Where in Eq. (1), $A, \tau_{1}$ and $K_{m}$ are the variables of the fatigue model. The function $E_{s}(t)$ represents the control variables consisting to electrical stimulations:

$$
E_{s}(t)=\frac{1}{\tau_{c}} \sum_{i=1}^{n} \eta_{i} H\left(t-t_{i}\right) R_{i} \exp \left(-\frac{t-t_{i}}{\tau_{c}}\right)
$$

associated to $n$ pulses $0=t_{1}<t_{2}<\ldots<t_{n}<T$ over the period. $H\left(t-t_{i}\right)$ is the Heaviside step function: $=0, t<t_{i},=1, t \geq t_{i}$

Table I gives definition and details of the symbols used in the above equations, $R_{i}$ in Eq. (1) is a scaling term that accounts for the nonlinear summation of the calcium transient in response to two consecutive pulses, and is given by:

$$
R_{i}=\left\{\begin{array}{rll}
1 & \text { for } & i=1 \\
1+\left(R_{0}-1\right) \exp \left(-\frac{t_{i}-t_{i-1}}{\tau_{c}}\right) & \text { for } & i>1
\end{array}\right.
$$

Note that in Eq. (3) appear the (discrete) control variables which consist into:

- The interpulse: $I_{i}:=t_{i}-t_{i-1}$ for $i>1$. If fixed, it is denoted $I$.

- The scaling factor $\eta_{i}$ which is the tuning factor of the applied electric intensity.

The second part of the model is the additional fatigue model which describes the changes of parameters $\left(A, K_{m}, \tau_{1}\right)$ in the force model during the fatigue conditions, it consists into the three differential equations Eqs. (5)-(7):

$$
\frac{d A}{d t}=-\frac{A-A_{\text {rest }}}{\tau_{f a t}}+\alpha_{A} F
$$




$$
\begin{gathered}
\frac{d K_{m}}{d t}=-\frac{K_{m}-K_{m, r e s t}}{\tau_{f a t}}+\alpha_{K_{m}} F \\
\frac{d \tau_{1}}{d t}=-\frac{\tau_{1}-\tau_{1, \text { rest }}}{\tau_{f a t}}+\alpha_{\tau_{1}} F
\end{gathered}
$$

Where again we refer to Table I for the definitions and details of the symbols of the fatigue model.

Concerning the force model, a first useful result is the following:

Proposition 1. Assuming $A, K_{m}$ and $\tau_{1}$ be fixed, the force model can be integrated by quadrature using a time reparameterization.

Proof. Eq. (2) can be written as:

$$
\frac{d F(t)}{d t}=a(t)+b(t) F(t)
$$

where $a(t)$ and $b(t)$ are obtained by integrating Eq. (1). Since $b(t)$ is $\neq 0$, Eq. (8) can be written as:

$$
\frac{d F(t)}{b(t) d t}=c(t)+F(t)
$$

and by setting

$$
d s=b(t) d t
$$

the integration of Eq. (9) is straightforward.

FES stimulation: clearly the electrical stimulation $E_{s}(t)$ : $0=t_{1}<t_{2}<\ldots<t_{n}<T$ decomposes into a period of stimulation $0=t_{1}<\ldots<t_{k}$ followed by a period of rest. Fig. 1 represents the stimulation pulses with $I=50 \mathrm{~ms}$, $\eta_{i}=0.8$ during a stimulation period of $1 \mathrm{~s} t_{1} \rightarrow t_{20}$ and $\eta_{i}=0$ during a rest period of $1 \mathrm{~s} t_{21} \rightarrow t_{40}$. In practice, period of stimulation and period of rest are repeated many times.

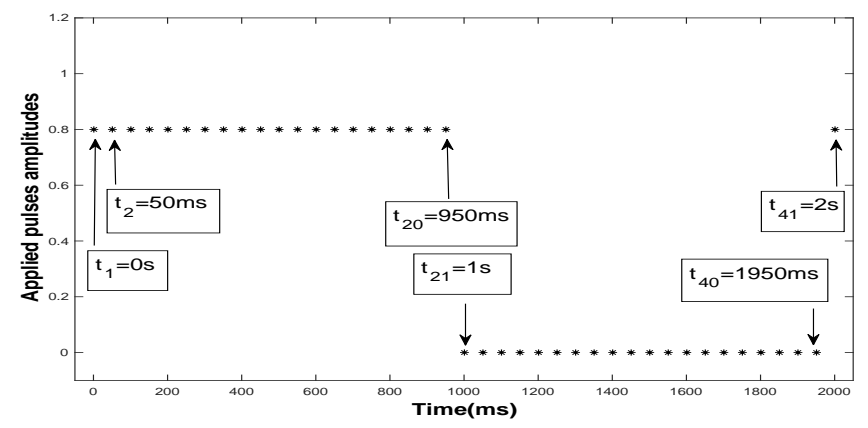

\begin{tabular}{|c|c|c|c|}
\hline \multicolumn{4}{|c|}{ MARGIN SETTINGS } \\
\hline Symbol & Unit & Value & description \\
\hline$\overline{C_{N}}$ & - & - & $\begin{array}{l}\text { Normalized amount of } \\
\mathrm{Ca}^{2+} \text {-troponin complex }\end{array}$ \\
\hline$F$ & $N$ & - & Force generated by muscle \\
\hline$t_{i}$ & $m s$ & - & Time of the $i^{t h}$ pulse \\
\hline$n$ & - & - & $\begin{array}{l}\text { Total number of } \\
\text { the pulses before time } t\end{array}$ \\
\hline$i$ & - & - & Stimulation pulse index \\
\hline$\tau_{c}$ & $m s$ & 20 & $\begin{array}{l}\text { Time constant that commands } \\
\text { the rise and the decay of } C_{N}\end{array}$ \\
\hline$R_{0}$ & - & 1.143 & $\begin{array}{l}\text { Term of the enhancement } \\
\text { in } C_{N} \text { from successive stimuli }\end{array}$ \\
\hline$A$ & $\frac{N}{m s}$ & - & $\begin{array}{l}\text { Scaling factor for the force and } \\
\text { the shortening velocity } \\
\text { of muscle }\end{array}$ \\
\hline$\tau_{1}$ & $m s$ & - & $\begin{array}{l}\text { Force decline time constant } \\
\text { when strongly bound } \\
\text { cross-bridges absent }\end{array}$ \\
\hline$\tau_{2}$ & $m s$ & 124.4 & $\begin{array}{l}\text { Force decline time constant } \\
\text { due to friction between actin } \\
\text { and myosin }\end{array}$ \\
\hline$K_{m}$ & - & - & $\begin{array}{l}\text { Sensitivity of strongly bound } \\
\text { cross-bridges to } C_{N}\end{array}$ \\
\hline$A_{\text {rest }}$ & $\frac{N}{m s}$ & 3.009 & $\begin{array}{l}\text { Value of the parameter } A \\
\text { when muscle is not fatigued }\end{array}$ \\
\hline$K_{m, \text { rest }}$ & - & 0.103 & $\begin{array}{l}\text { Value of the parameter } K_{m} \\
\text { when muscle is not fatigued }\end{array}$ \\
\hline$\tau_{1, \text { rest }}$ & $m s$ & 50.95 & $\begin{array}{l}\text { The value of the parameter } \tau_{1} \\
\text { when muscle is not fatigued }\end{array}$ \\
\hline$\alpha_{A}$ & $\frac{1}{m s^{2}}$ & $-4.010^{-7}$ & $\begin{array}{l}\text { Coefficient for the force-model } \\
\text { parameter } A \text { in the fatigue } \\
\text { model }\end{array}$ \\
\hline$\alpha_{K_{m}}$ & $\frac{1}{m s N}$ & $1.910^{-8}$ & $\begin{array}{l}\text { Coefficient for the force-model } \\
\text { parameter } K_{m} \text { in the fatigue } \\
\text { model }\end{array}$ \\
\hline$\alpha_{\tau_{1}}$ & $\frac{1}{N}$ & $2.110^{-5}$ & $\begin{array}{l}\text { Coefficient for force-model } \\
\text { parameter } \tau_{1} \text { in the fatigue } \\
\text { model }\end{array}$ \\
\hline$\tau_{f a t}$ & $s$ & 127 & $\begin{array}{l}\text { Time constant controlling the } \\
\text { recovery of }\left(A, K_{m}, \tau_{1}\right)\end{array}$ \\
\hline
\end{tabular}

Fig. 1. Stimulation pulses example (amplitude $\eta_{i}=0.8$ during the stimulation time of $1 \mathrm{~s}$ and $\eta_{i}=0$ during the rest time of $1 \mathrm{~s}$ with a constant interpulse $I=50 \mathrm{~ms}$ )
TABLE I

\section{ESTIMATION OF THE STATE VARIABLES OF THE FORCE FATIGUE MODEL}

The model used for this study (five state variables) is based on force measurements collected from a set of subjects. Thus, the accuracy of the calculated parameters is directly related to these persons. In this study, we suppose that initial conditions are different following the subject under study. That is why, we need to estimate some of these five initial conditions. Indeed, from a first analysis we can deduce that the rest values $C_{N}\left(t_{1}\right)=0$ and $F\left(t_{1}\right)=0$ of $C_{N}$ and $F$ respectively are realistic and don't need any estimation. The remaining parameters are $A_{\text {rest }}, K_{m \text {,rest }}$ and $\tau_{1, \text { rest }}$. Concerning $K_{m \text {,rest }}$, a sensibility study is realized in order to determine its effect on the force variation.

\section{A. Sensibility study of the force versus state variables}

1) Sensibility study of the force versus $K_{m}$ : The force evolution is compared for $K_{m, \text { rest }}$ and different values $K_{m, r e s t}^{\prime}( \pm 30 \%$ of error) for $I=10 \mathrm{~ms}, 50 \mathrm{~ms}$ and $100 \mathrm{~ms}$ (see Fig. 2 for $I=10 \mathrm{~ms}$ ). In the case of $I=10 \mathrm{~ms}$, the maximum force error is of $-0.3 \%$. Following Interpulse 


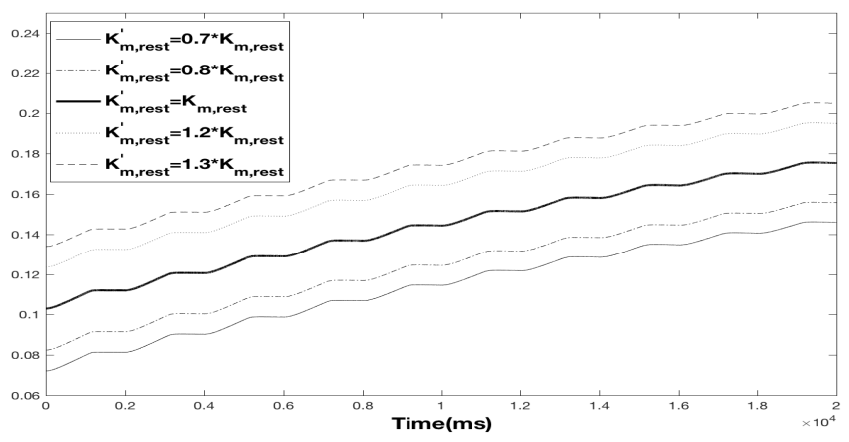

Fig. 2. Evolution of $K_{m}$ for different initial conditions (case of $I=10 \mathrm{~ms}$ )

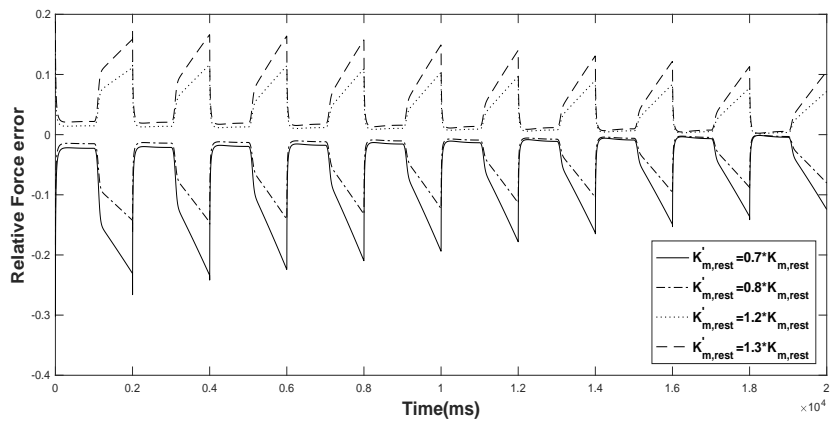

Fig. 3. Relative error of the force for a well known and erroneous $K_{m}$ initial condition (case of $I=10 \mathrm{~ms}$ )

value, the maximum force error is obtained for $I=100 \mathrm{~ms}$ $(-1.3 \%)$ which means that a tolerance of $\pm 30 \%$ gives force evolution with good accuracy.

2) Sensibility study of the force versus a part of $A$ and $\tau_{1}$ derivatives: We compare the derivative of $A$ and $\tau_{1}$ (Eq. (5) and Eq. (7), respectively) with the "simplified" following derivatives (we assume a maximum stimulation time of 20s):

$$
\begin{gathered}
\frac{d A}{d t}=\alpha_{A} F \\
\frac{d \tau_{1}}{d t}=\alpha_{\tau_{1}} F .
\end{gathered}
$$

Using (Eq. (5) and Eq. (7)) and (Eq. (11) and Eq. (12)), the force error was computed in the cases of $\eta=0.1,0.5$ and 1 with $I=10 \mathrm{~ms}, 100 \mathrm{~ms}$ (during 10 stimulation-rest periods of $2 \mathrm{~s}$ ).

The figures (Fig. 4), (Fig. 5) and (Fig. 6) represent the relative error for $A, \tau_{1}$ and $F$, respectively. The worst case is obtained for $\eta_{i}=1, I=100 \mathrm{~ms}$ where the relative error reaches $5.4 \%$. The figure (Fig. 7) shows the force evolution for the two cases.

From this, we can define a "simplified model" (Eq. (1), Eq. (2), Eq. (3), Eq. (4), Eq. (6), Eq. (11) and Eq. (12)). This simplified model will be used to calculate the correction term of the observer (see the following section).

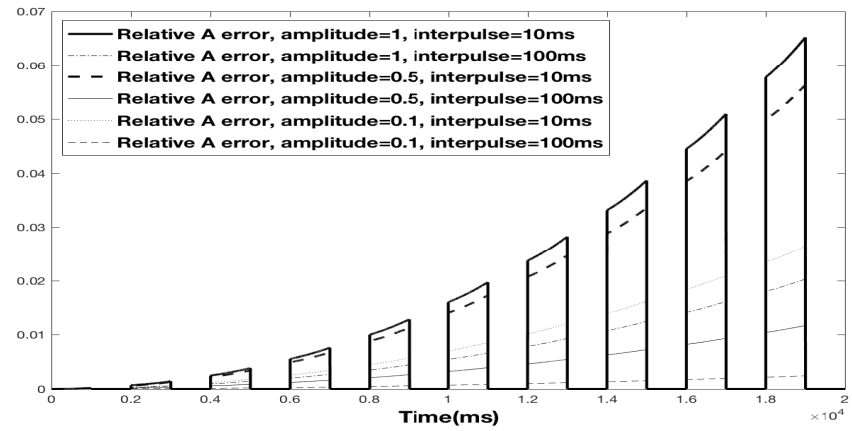

Fig. 4. Relative error between $A$ and its approximated value for different stimulations

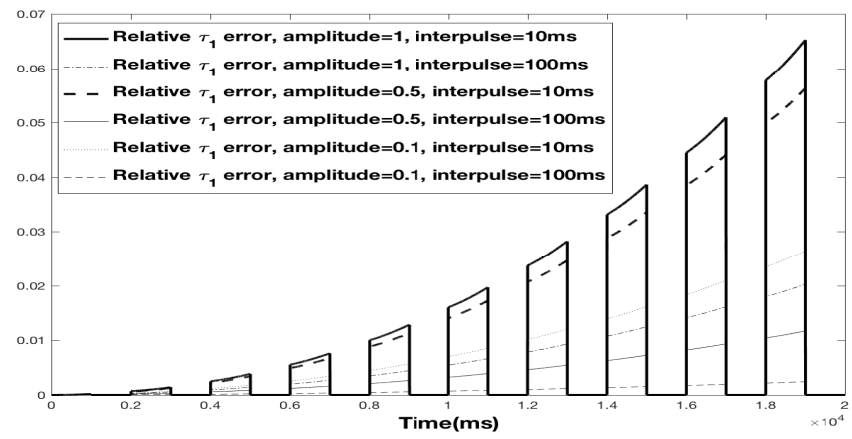

Fig. 5. Relative error between $\tau_{1}$ and its approximated value for different stimulations

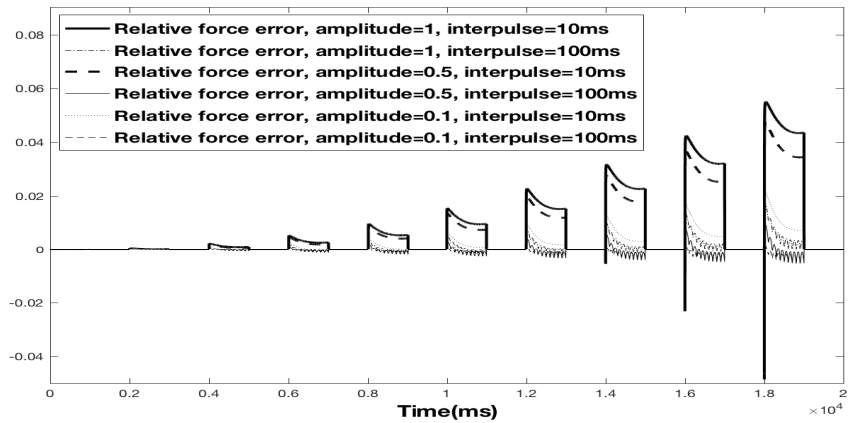

Fig. 6. Evolution of $F$ and its approximated value for different stimulations

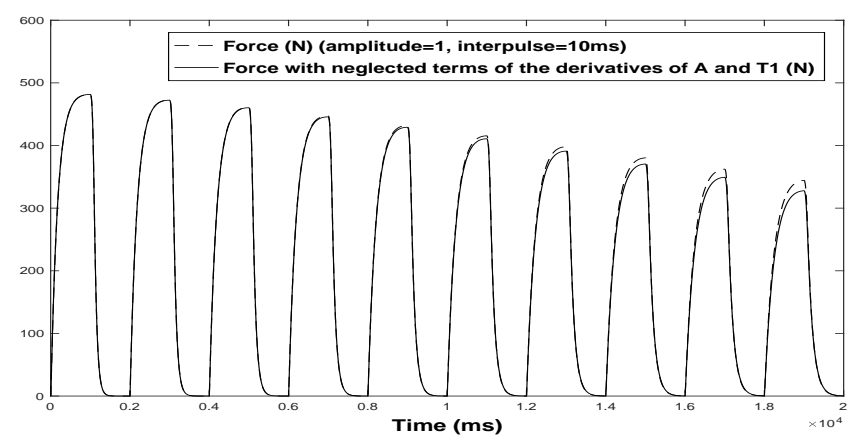

Fig. 7. The force evolution in the case of $\eta_{i}=1$ and $I=10 \mathrm{~ms}$ (force approximation worst case) 


\section{B. High-gain observer synthesis for the estimation of $A$ and} $\tau_{1}$

In this section, we design a modified version of the standard high-gain observer given in [11] taking into account the specific structure of the problem.

The system defined by the force equation Eq. (2) and the fatigue model (Eq. (5) and Eq. (7)) can be rewritten as the single input-output system:

$$
\left\{\begin{array}{l}
\dot{x}(t)=\beta^{m}\left(t, E_{s}(t)\right) f\left(x(t), E_{s}(t)\right) \\
y(t)=h(x(t))=F(t)
\end{array}\right.
$$

with $x=\left(F, A, \tau_{1}\right) \in \mathbb{R}^{3}, y \in \mathbb{R}, E_{s} \in \mathbb{R}$.

$$
\beta=\frac{C_{N}}{C_{N}+K_{m}}, 0<\beta<1
$$

Note that in Eq. (13)), $K_{m}$ is not a state variable thanks to the robustness of the solution with respect to this variable (see Sensibility study of the force versus $K_{m}$ ). We introduce the change of variables $\phi$ :

$$
\left\{\begin{array}{l}
\phi: \mathbb{R}^{3} \rightarrow \mathbb{R}^{3} \\
x \rightarrow \phi(x)=\left[h(x), L_{f_{1}}(h(x)), L_{f_{1}}^{2}(h(x))\right]
\end{array}\right.
$$

$f_{1}\left(x(t), E_{s}(t)\right)$ being the simplified expression of $f\left(x(t), E_{s}(t)\right)$ and calculated from the simplified model ((2), (11) and (12)). The simplification allows to avoid the ill-conditioning of $\left(\frac{\partial \phi}{\partial x}(\hat{x}(t))^{-1}\right.$. The modified high-gain observer is defined as:

$$
\begin{aligned}
\dot{\hat{x}}(t)= & \beta^{m} f\left(\hat{x}(t), E_{s}(t)\right) \\
& -\beta^{m}\left(\frac{\partial \phi}{\partial x}(\hat{x}(t))^{-1} S_{\theta}^{-1} C^{T}(C \hat{x}(t)-y(t))\right.
\end{aligned}
$$

with $m$ is a positive integer. $S_{\theta}$ is a symmetric positive definite matrix given by the following Lyapunov equation:

$$
\theta S_{\theta}(t)+A^{T} S_{\theta}(t)+S_{\theta}(t) A=C^{T} C
$$

where $\theta$ is a tuning parameter,

$$
A=\left(\begin{array}{lll}
0 & 1 & 0 \\
0 & 0 & 1 \\
0 & 0 & 0
\end{array}\right), C=\left(\begin{array}{lll}
1 & 0 & 0
\end{array}\right) .
$$

The terms of this matrix $S_{\theta}=\left[S_{\theta}(l, k)\right]_{1 \leq l, k \leq 3}$ have the following form:

$S_{\theta}(l, k)=(-1)^{l+k}\left(\begin{array}{c}l+k-2 \\ k-1\end{array}\right) \theta^{-(l+k-1)},\left(\begin{array}{c}n \\ k\end{array}\right)=$ $\frac{n !}{(n-k) ! k !}$

In the particular case of the force fatigue model, $\beta(t)$ is piecewise smooth, the lack of regularity is numerically bypassed by the choice of the integer $m$. For example, for $I=10 \mathrm{~ms}, m=3$ is sufficient to estimate the whole variables. However, for $I=25 \mathrm{~ms}, \mathrm{~m}$ must be at least equal to 5 (see observer simulations below).

\section{Muscular force control}

The estimation of the state variables vector is used as an initial variables vector to perform a predictive strategy (over an horizon of $H O R$ equal interpulse intervals) to bring the mean force value $F_{\text {mean }}$ over $H O R$ (see procedure below) to a force reference (see [12]). The interpulse $I$ is fixed and $\eta_{i}$ is the control variable.

We use a numerical integration time called $S t e p_{\text {int }}$, and for a fixed horizon $H O R$, define $\operatorname{Data}_{F}$ by:

$$
\operatorname{Data}_{F}=H O R * \frac{I}{\text { step }_{\text {int }}}
$$

\section{1) Algorithm:}

1) Give Final $_{t}$ ( $I$ is a submultiple of Final $_{t}$ ), $k=1$

2) $C_{N}\left(t_{k}\right), F\left(t_{k}\right), \hat{A}\left(t_{k}\right), \hat{\tau_{1}}\left(t_{k}\right), K_{m}\left(t_{k}\right)$

3) $F_{\text {mean }}=\frac{1}{\operatorname{Data}_{F}} \sum_{i=1}^{\operatorname{Data}_{F}} F\left(t_{k}+i *\right.$ Step $\left._{\text {int }}, E_{s}\right)$ with:

$$
\begin{aligned}
E_{s}=\frac{1}{\tau_{c}} \sum_{i=1}^{k+(H O R-1)} & \left(\eta_{i} H\left(t_{\text {HOR }}-t_{i}\right)\right. \\
& \left.* R_{i} \exp \left(-\frac{t_{H O R}-t_{i}}{\tau_{c}}\right)\right)
\end{aligned}
$$

and: $\eta_{i}=\eta_{k}$ for $i=k, k+1, \ldots, k+(H O R-1)$, $t_{H O R}=(k+H O R) \times I$

4) $\bar{\eta}_{k}=\bar{\eta}\left(t_{k}\right)=\underset{\eta_{k} \in[0,1]}{\operatorname{argmin}}\left(F_{\text {mean }}-F_{\text {ref }}\right)^{2}$

5) Compute $\left.\left.\hat{A}(t), \hat{\tau}_{1}(t), t \in\right] t_{k}, t_{k+1}\right]$

6) if $t_{k+1}=$ Final $_{t} \Rightarrow$ stop, else, $k=k+1$, back to 2

In this case (fixed $I$ and $H O R$ ), only $I=10 \mathrm{~ms}(100 \mathrm{~Hz})$ is considered for the computation of the predictive control.

\section{Simulation Results}

MATLAB/SIMULINK software was used to perform the different simulations with Runge-Kutta solver and an integration time step $p_{i n t} 0=1 \mathrm{~ms}$. The force-fatigue model depends on six free model parameters $\left(\tau_{c}, A, \tau_{1}, \tau_{2}, R_{0}\right.$, and $\left.K_{m}\right)$. The values of these parameters were computed in the case of a typical subject.

\section{A. Observer and control simulation Results for $H O R=10$}

For estimation simulation, we consider the worst case of $+30 \%$ of error of $K_{m}$. Fig. (8) and Fig. (9) represents the $A$ estimates for $100 \mathrm{~Hz}(I=10 \mathrm{~ms})$ and $40 \mathrm{~Hz}(I=25 \mathrm{~ms})$, respectively. Fig. (10) and Fig. (11) are the $\tau_{1}$ estimates for $100 \mathrm{~Hz}$ and $40 \mathrm{~Hz}$. $\hat{A}$ converges after $50 \mathrm{~ms}$ when $I=10 \mathrm{~ms}$ and $100 \mathrm{~ms}$ when $I=25 \mathrm{~ms}$. Concerning $\hat{\tau_{1}}$, it converges after $75 \mathrm{~ms}$ when $I=10 \mathrm{~ms}$ and $200 \mathrm{~ms}$ when $I=25 \mathrm{~ms}$. Large $I$ seems to delay the convergence of the observer. 


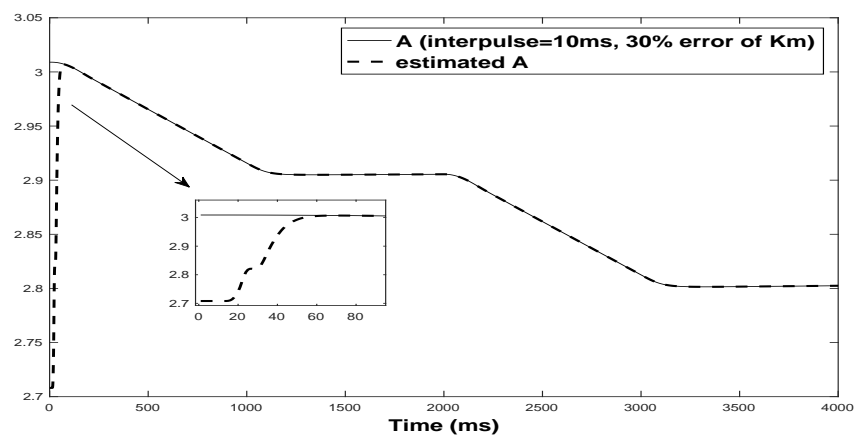

Fig. 8. Evolution of $A$ and $\hat{A}$ for $I=10,30 \%$ error of $K_{m}$

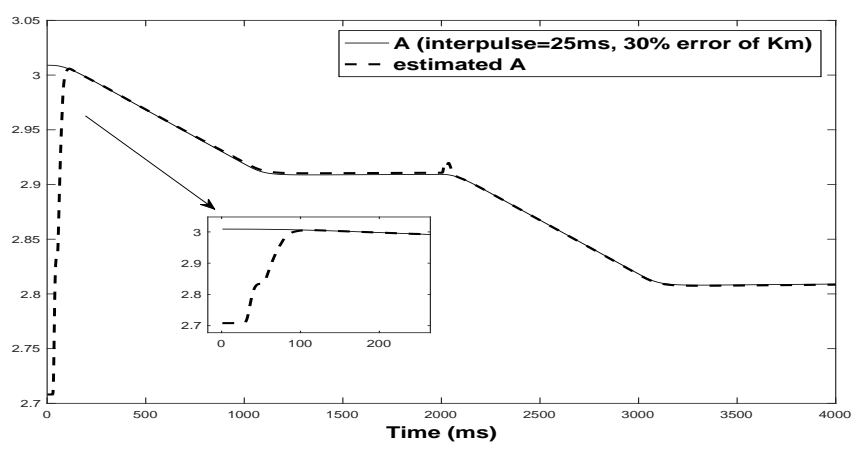

Fig. 9. Evolution of $A$ and $\hat{A}$ for $I=25,30 \%$ error of $K_{m}$

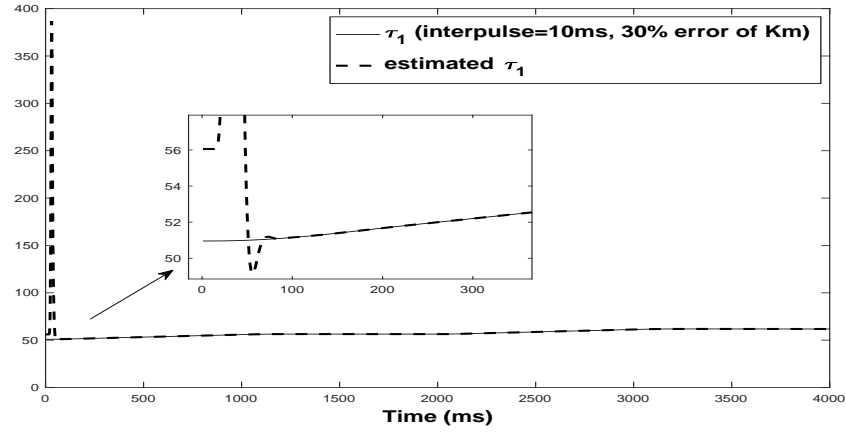

Fig. 10. Evolution of $\tau_{1}$ and $\hat{\tau_{1}}$ for $I=10,30 \%$ error of $K_{m}$

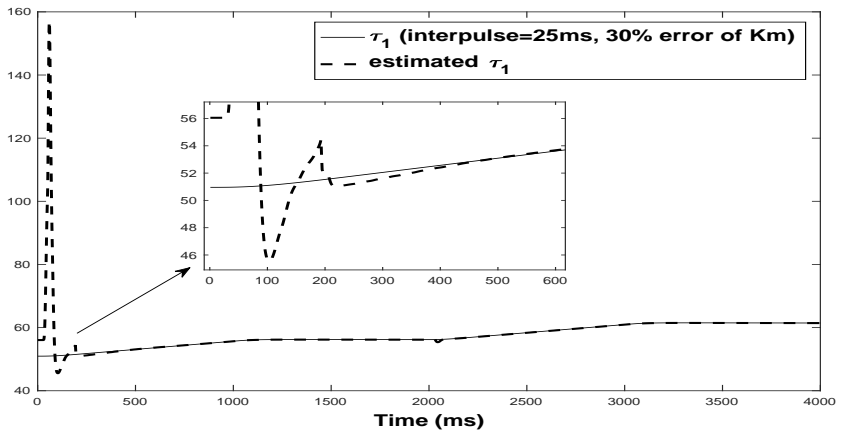

Fig. 11. Evolution of $\tau_{1}$ and $\hat{\tau_{1}}$ for $I=25,30 \%$ error of $K_{m}$
Fig. (12) represents the control strategy (for a prediction horizon $H O R=10$ ) based on the proposed observer for $I=25 \mathrm{~ms}$ and a mean force reference of $250 \mathrm{~N}$. It can be observed that the force mean value converges to the force reference after $200 \mathrm{~ms}$.

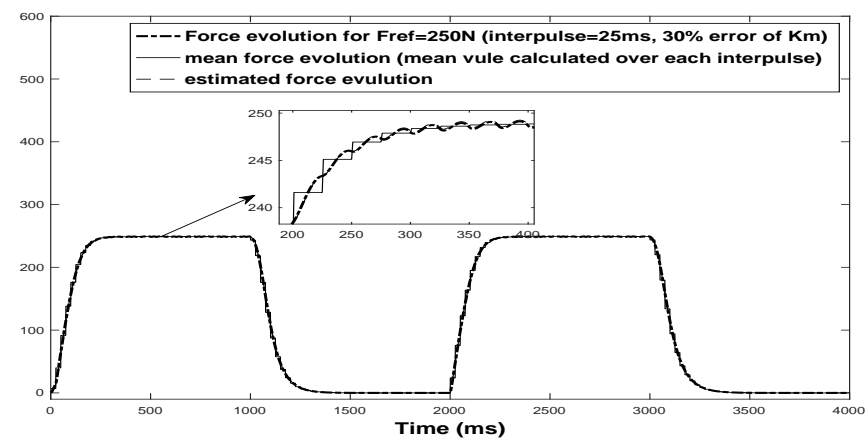

Fig. 12. Evolution of $F, \hat{F}$ and $F$ mean value over $I$ for $I=25,30 \%$ error of $K_{m}, F_{r e f}=250 \mathrm{~N}$

\section{B. Control simulation results}

1) Control precision following the prediction horizon: The choice of $H O R$ in Fig. (12) is motivated by different tests (different stimulation frequencies and force reference values). Fig. (13) and Fig. (14) represent control results for $\left(I=10 \mathrm{~ms}, F_{\text {ref }}=50 \mathrm{~N}\right)$ and $\left(I=50 \mathrm{~ms}, F_{\text {ref }}=330 \mathrm{~N}\right)$. In these two cases, the more adequate prediction horizon is $H O R=10$ to give short response time with a low overshoot.

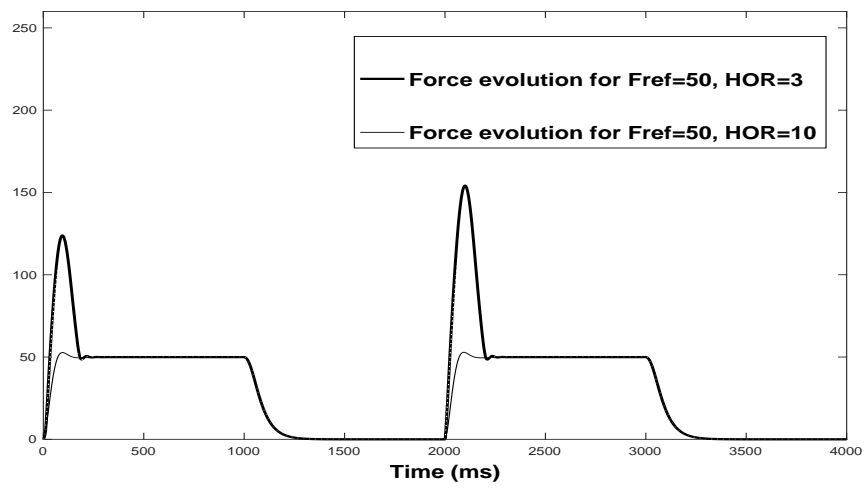

Fig. 13. Evolution of $F$ for $I=10 \mathrm{~ms}, F_{\text {ref }}=50 \mathrm{~N}$ and different prediction horizon lengths 


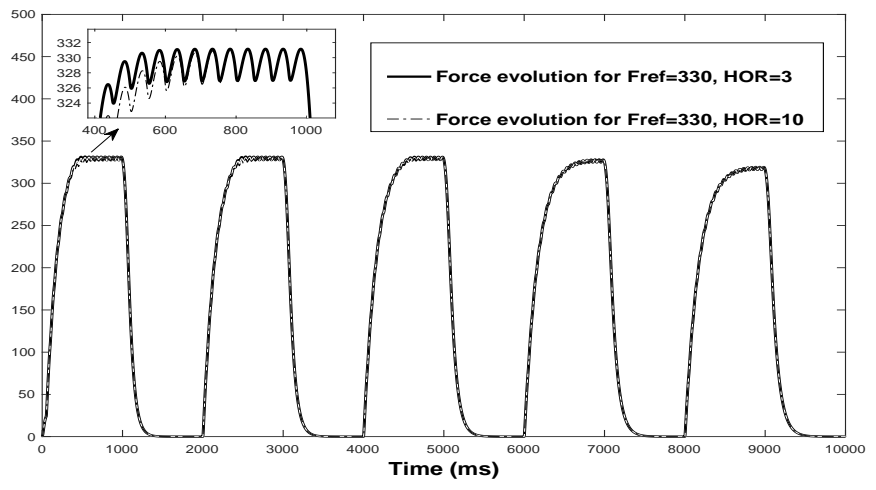

Fig. 14. Evolution of $F$ for $I=50 \mathrm{~ms}$, Fref $=330 \mathrm{~N}$ and different prediction horizon lengths

2) Fatigue effect: Fig. (15) and Fig. (16) are the force response and the control (pulses amplitudes) applied to bring $F_{\text {mean }}$ to $250 \mathrm{~N}$, respectively. It can be observed that starting from the $4^{\text {th }}$ period, the pulses amplitudes saturate at 1 which means that the FES is reaching its maximum value to counteract the fatigue effect.

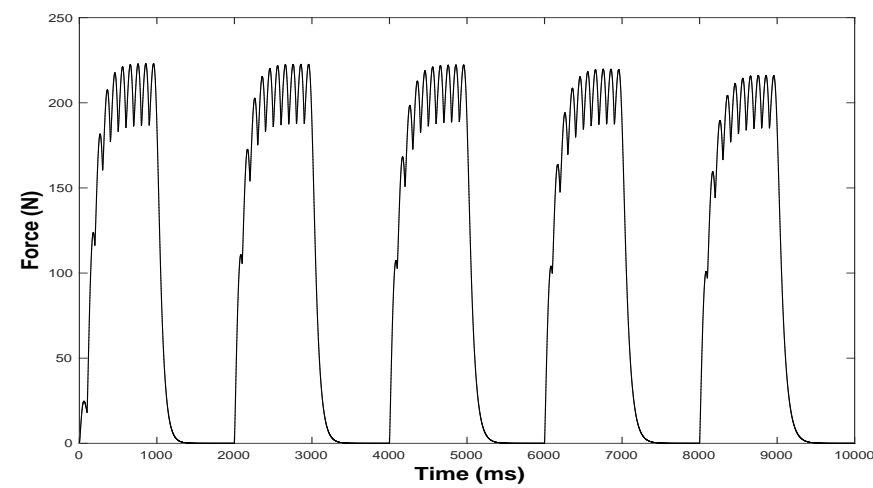

Fig. 15. Evolution of $F$ for Fref $=210 N$ and $I=100 \mathrm{~ms}$ along 5 periods, $H O R=10$

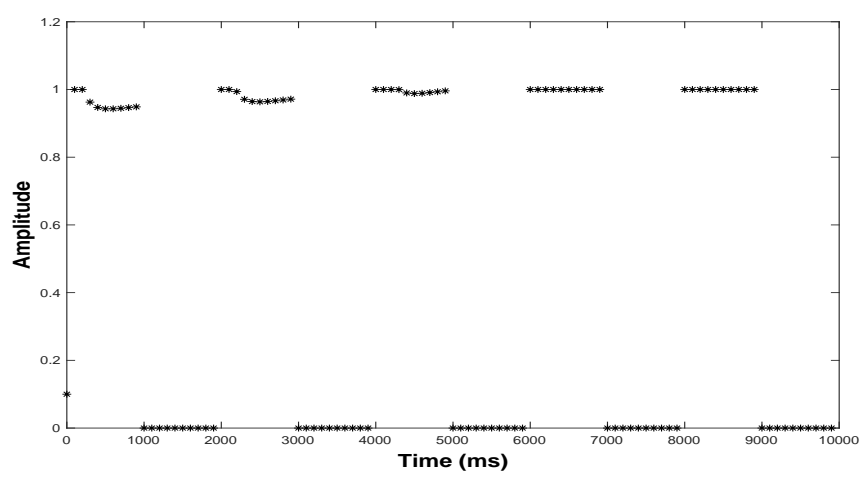

Fig. 16. Evolution of the stimulation amplitude for Fref $=210 \mathrm{~N}$ and $I=100 \mathrm{~ms}$ along 5 periods

\section{CONCLUSION}

Our study aims to present control-observer techniques into the FES control of the force-fatigue model of Ding. The proposed observer deals with the specific case of a continuous system with a discrete control. The correction term is related to the applied interpulse. The used nonlinear MPC technique to control the force level depends on the optimum search space which is not necessary convex. Despite the fact that the found minimum could not be a global minimum, appropriate receding horizon allowed to reach the force reference. Numerical simulations validate these techniques. This work is the first step of a complete study in the frame of (closed loop) optimal control analysis of the problem.

\section{REFERENCES}

[1] J. Ding, L.-W. Chou, T. M. Kesar, S. C. Lee, T. E. Johnston, A. S. Wexler, and S. A. Binder-Macleod, "Mathematical model that predicts the force-intensity and force-frequency relationships after spinal cord injuries," Muscle \& nerve, vol. 36, pp. 214-222, 2007.

[2] J. Bobet and R. B. Stein, "A simple model of force generation by skeletal muscle during dynamic isometric contractions," IEEE Transactions on Biomedical Engineering, vol. 45, pp. 1010-1016, 1998.

[3] L. F. Law and R. Shields, "Mathematical models of human paralyzed muscle after long-term training," Journal of biomechanics, vol. 40, pp. 2587-2595, 2007.

[4] J. Ding, S. A. Binder-Macleod, and A. S. Wexler, "Two-step, predictive, isometric force model tested on data from human and rat muscles," Journal of applied physiology, vol. 85, pp. 2176-2189, 1998.

[5] J. Ding, A. S. Wexler, and S. A. Binder-Macleod, "Development of a mathematical model that predicts optimal muscle activation patterns by using brief trains," Journal of Applied Physiology, vol. 88, pp. 917$925,2000$.

[6] J. Ding, A. S. Wexler, and S. A. Binder-Macleod, "A predictive model of fatigue in human skeletal muscles," Journal of Applied Physiology, vol. 89, pp. 1322-1332, 2000.

[7] J. Ding, A. S. Wexler, and S. A. Binder-Macleod, "Mathematical models for fatigue minimization during functional electrical stimulation," Journal of Electromyography and Kinesiology, vol. 13, pp. 575-588, 2003.

[8] A. Ben Hmed, T. Bakir, A. Sakly, and S. Binczak, "Controlling muscular force by functional electrical stimulation using intelligent pid," in Sciences and Techniques of Automatic Control and Computer Engineering (STA), 2015 16th International Conference on, pp. 75-79, 2015.

[9] B. D. Doll, N. A. Kirsch, and N. Sharma, "Optimization of a stimulation train based on a predictive model of muscle force and fatigue," IFAC-PapersOnLine, vol. 48, pp. 338-342, 2015.

[10] A. Maillard, M. Yochum, T. Bakir, and S. Binczak, "On the control of a muscular force model including muscular fatigue," in $20157 \mathrm{th}$ International IEEE/EMBS Conference on Neural Engineering (NER), pp. 828-831, 2015.

[11] J. Gauthier, H. Hammouri, and S. Othman, "A simple observer for non linear systems application to bioreactors," IEEE Trans. Automat. Control, vol. 37, pp. 875-880, 1992.

[12] L. Wang, "Model predictive control system design and implementation using matlab," 2009. 